\title{
The Effectiveness of Metacognitive Training on Psychological Well-Being and Quality of Life in Pregnant Women: A Quasi-Experimental Study
}

\author{
Afsaneh Parto ${ }^{1}$, Mojgan Hayati ${ }^{* *}$ \\ 1. MA, School of Counseling, Payam-e Noor University, Qazvin, Iran \\ 2. Assistant Professor, Department of Psychology, Payam-e Noor University, Tehran, Iran
}

\begin{tabular}{lr}
\hline \multicolumn{2}{c}{ Article Info } \\
\hline & \\
Received: & $2018 / 05 / 21$ \\
Accepted: & $2018 / 05 / 27$ \\
Published Online: & $2019 / 05 / 22$
\end{tabular}

DOI: $10.30699 /$ sjhnmf.27.2.125

Original Article

Use your device to scan and read the article online

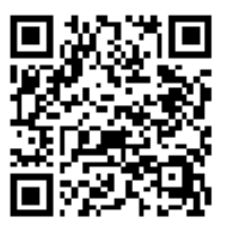

\section{Abstract}

Introduction: Teaching metacognition is one of the methods for improving the psychological well-being and quality of life of pregnant women. The purpose of this study was to investigate the effectiveness of meta-cognitive education on the psychological well-being and quality of life of pregnant women.

Methods: This was a semi experimental study with pre-test and post-test design and control group. The statistical population of this study included all pregnant women who referred to Namazi Hospital in Shiraz in 2016. Sample size included 60 people from this community, who were randomly divided into two groups of 30 subjects. A psychological well-being questionnaire and a quality of life questionnaire were used for data collection; data was analyzed using one-variable covariance analysis, and SPSS 22.

Results: The mean (standard deviation) of the students in the experimental group was $33.4 \pm 2.8$ and the control group was $34.7 \pm 2.9$. The results of this study showed that the pre-test of well-being in the experimental group was 85.6 which increased to 99.2 in the post-test $(P<0.0001, \mathrm{~F}=44.20)$, but the pre-test of the control group was 84.8 , which reached to 85.4 in the post-test $(P<0.05)$. The pre-test of quality of life in the experimental group was 71.2 which increased to 89.7 in the post-test $(P<0.0001, \mathrm{~F}=30.70)$, but the pre-test of the control group was 86.5 , which was 87.1 in the post-test $(P<0.05, \mathrm{~F}=30.70)$.

Conclusion: It can be concluded that metacognitive education was effective in increasing the psychological well-being and the quality of life of pregnant women.

Keywords: Meta-Cognition, Psychological Well-Being, Quality of Life, Pregnancy

\section{Corresponding Information \\ Mojgan Hayati, Department of Psychology, Payam-e Noor University, Tehran, Iran. \\ Email: m.hayati@bzpnu.ac.ir}

Copyright (C) 2019, This is an original open-access article distributed under the terms of the Creative Commons Attribution-noncommercial 4.0 International License which permits copy and redistribute of the material just in noncommercial usages with proper citation.

How to Cite This Article:

Parto A, Hayati M. The Effectiveness of Metacognitive Training on Psychological Well-Being and Quality of Life in Pregnant Women: A Quasi-Experimental Study. Avicenna J Nurs Midwifery Care. 2019; 27(2):125-132 


\title{
مجلهُ مراقبت يرستارى و مامايى ابن سينا - شايا الكترونيك: بو

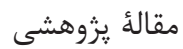

\author{
اثربخشى آموزش فراشناخت بر بهزيستى روانشناختى و كيفيت زندكى زنان باردار:

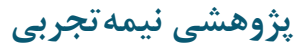

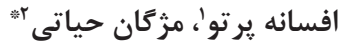

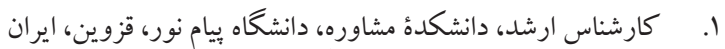

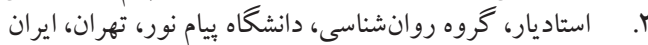

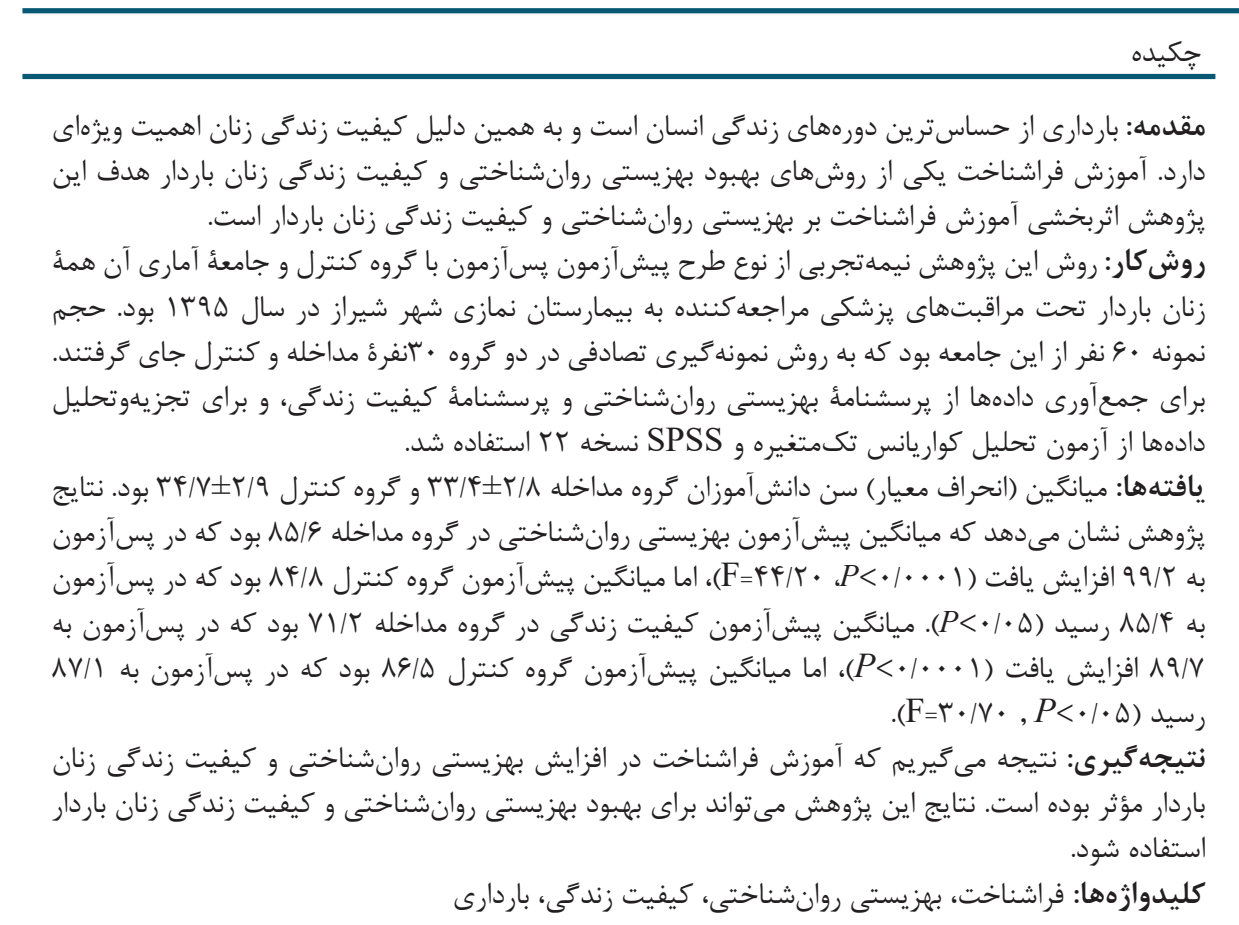

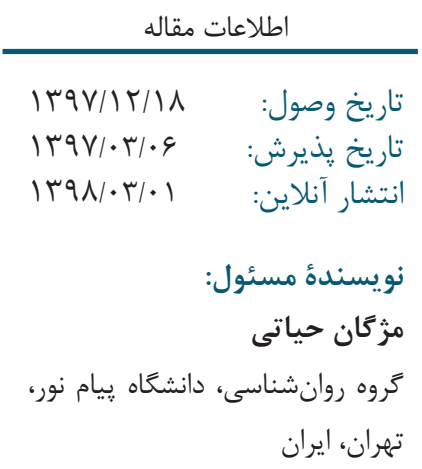

يست الكترونيك:

m.hayati@bzpnu.ac.ir

$$
\text { كليدوازهها: فراشناخت، بهزيستى روانشناختى، كيفيت زندگى، باردارى }
$$

مقله

بهزيستى روانشناختى را شادكامى ذهنى، لذت و اجتناب از

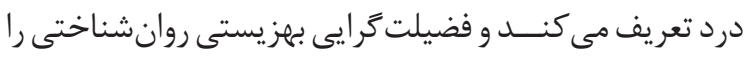

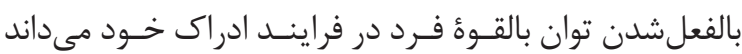
[ب]]. فراهمكردن منابع حمايتى عاطفى، مادى و اطلاعاتى

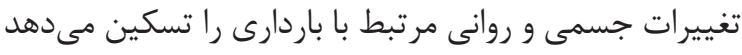

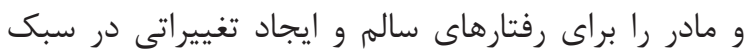

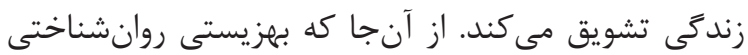
حائلى در مقابل استرس است در زنان باردارى كه استرس

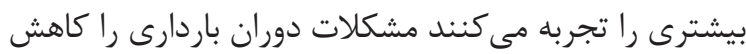

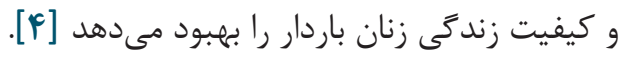

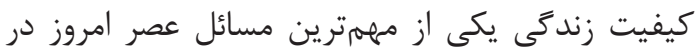
مراقبت سلامتى و يكى از بزركترين اهداف بهداشتى براى إنى

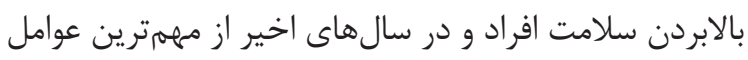

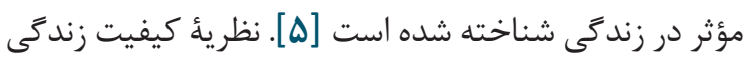
بر رضايتمندى از زندكى و تجربهُ ذهنى سلامت، ميزان
باردارى از حساسترين دورههاى زندگى انسان است.

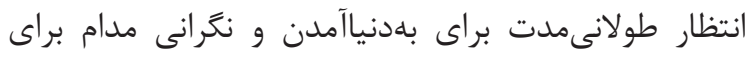

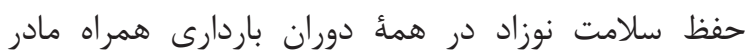

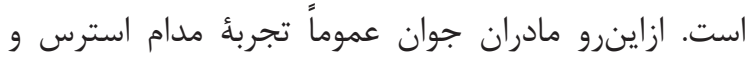
اضطراب دارند و بهداشت روانى دوران باردارى از مسائلى إنى

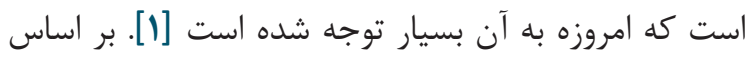
يزوهشهاى انجامشده زنان باردار به دليل اينكه زمان بيشترى به سلامتى جنين فكر مى كنند بسيار حساسترند.

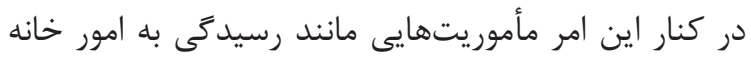

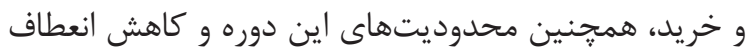

مرتبط با آن استرس را در اين افراد افزايش مىدهد [باين. در دوران باردارى بهزيستى روانشناختى براى سلامتى

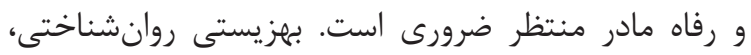

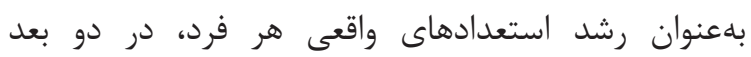
لذترَايسى و فضيلتخرايى تعريـف مىشود. لذترَايى 
دارد. بنابراين هدف اين يزوهش اثربخشى آموزش فراشناخت بر بهزيستى روانشناختى و كيفيت زندكى زنان باردار است.

$$
\text { روش بررسى }
$$

روش اين يزوهش نيمهتجربى از نوع طرح پِيش آزمون پِس آزمون با گروه كنترل و جامعهُ آمارى آن همؤ زنان باردار

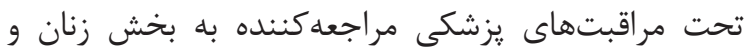
زايمان بيمارستان نمازى شهر شيراز در سال هوبا برأ بود.

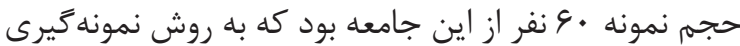
دردسترس و بهطور تصادفى به دو گروه • انفره مداخله و

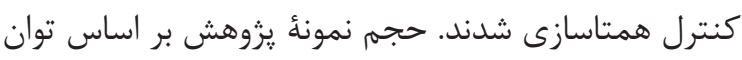

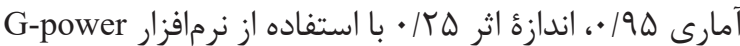

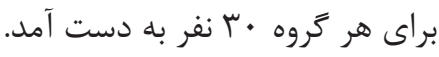
ملاكهاى ورود به يزوهش عبارت بود از: يرستاران با بان

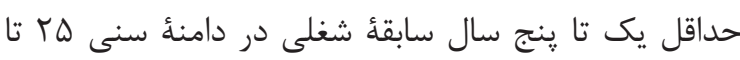

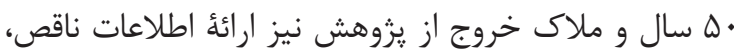
نامعتبر و مشاركتنكردن در يزوهش بود. نحوهُ اجرا به اين صورت بود كه •4 نفر به صورت تصادفى انتخاب و در كروه آزمايش و كنترل به صورت تصادفى جايكزين شدند (هر بهر

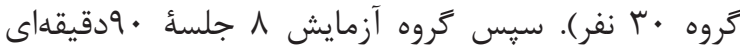
آموزش فراشناخت را به صورت تروهى دريافت كرد و كروه

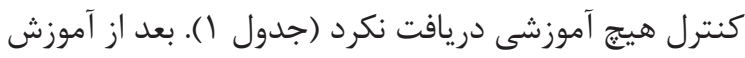

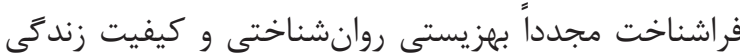
كروه آزمايش و كنترل (يسآزمون) تجزيهوتحليل شد شد

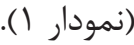

ملاحظات اخلاقى يزوهش به اين شرح بود: ا. همأ افراد

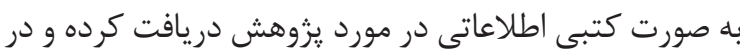
صورت تمايل در يزوهش مشاركت مى كنند. r. اين اطمينان

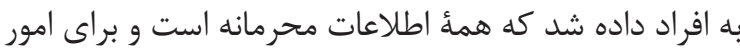

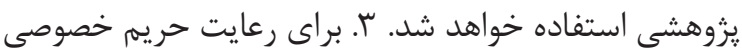
نام و نام خانوادگى شركت كنند كان ثبت نشد.

\section{برسشنامهُ مقياس بهزيستى روانشناختى}

(RSPWB-18)

در اين يرسشنامه كه براى بزركسالان تهيه شده است آزمودنى بايد در طيف ليكرت عدرجهاى (1. كاملاً مخالفم برال

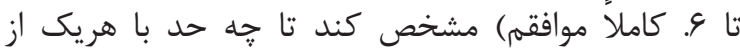
عبارتها موافق يا مخالف است. در اين يرسشنامه نمرات

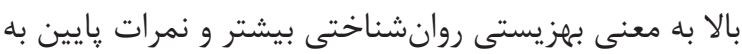

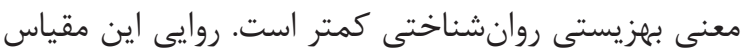

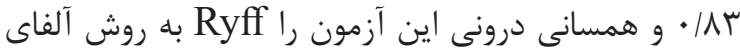

مثبتبودن تجربهُ درونى انسان (مثل افكار و احساسات) اشاره مى كند [9]. براى بهبود بهزيستى روانشناختى و

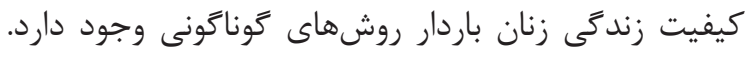
يكى از اين روشها درمان فراشناخت است. فراشناخت فرايند شناختى يا هر دانشى است كه در ارزيابى، بازبينى يا كنترل شناخت سهيم است. در يك سطح فراشناخت جنبأ عمومى شناخت است كه در همأ امور شناختى دخالت دارد. فراشناخت مفهومى خند وجهى شامل دانش (باورها)، فرايند و راهبردهايى است كه شناخت را ارزيابى يا كنترل مى كند

اكثر فعاليتهاى شناختى به عوامل فر اشناختى وابستهاند. علاوه بر اين اطلاعاتى كه از بازبينى فراشناختى يديد مى آيد اغلب بهعنوان احساسهاى ذهنى تجربه مىشود كه بر رفتار

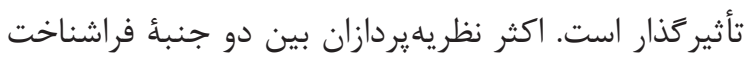
يعنى دانش فراشناختى و تنظيم فراشناختى تمايز قائل شدهاند. دانش فراشناختى شامل اطلاعاتى است كه افراد در مورد شناخت خود و در مورد عوامل مرتبط به تكليف يا راهبردهاى يادگيرى دارند. تنظيم فراشناختى انواع اعمال

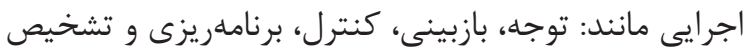

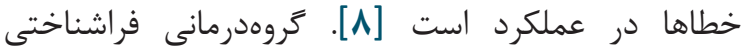
باورهاى مثبت دربارء افسردىى، كيفيت زندكى، ياسخدهى

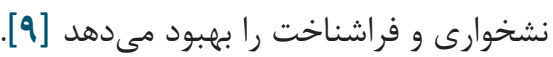
اثربخشى درمان فراشناختى بر علائم افسردىى و كيفيت زندكى بيماران افسرده اساسى نشان مىدهد كه دراحتى دران فراشناخت بر علائم افسردگى و كيفيت زندگى بيمار ان افسردة

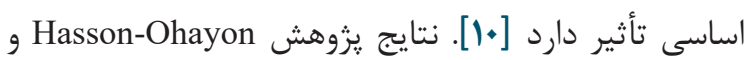
همكاران (b| • [) [II] در افراد مبتلا به اسكيزوفرنى نشان مىدهد كه تشخيص اسكيزوفرنى و ظرفيت فراشناختى،

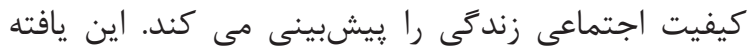

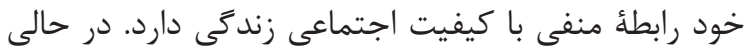

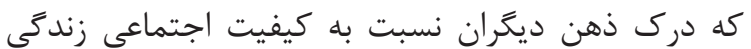
مثبت داشت. همجنين يزوهش Barahmand و همكاران

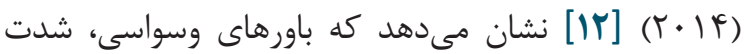
كلى وسواس فكرى و باورهاى فراشناختى با كيفيت كلى نمرات كيفيت زندكى مرتبط است. يافتهها نشان مى دهد كه باورهاى فراشناختى مرتبط با شدت علائم وسواس فكرى با

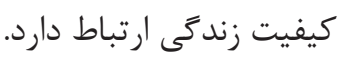
فرضئُ اصلى اين يزوهش اين بود كه آموزش فراشناخت بر بهزيستى روانشناختى و كيفيت زندگى زنان باردار تأثير 
تأييد، ضرايب همسانى درونى خردهمقياسهاى ^رانأُ آن

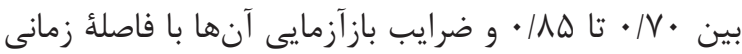

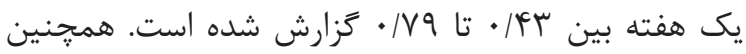

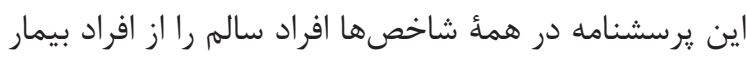

تفكيك مى كند [19].

جلسات آموزش فراشناخت دو روز در هفته و هر روز مدت •q دقيقه اجرا شد. براى بررسى و تجزيهوتحليل

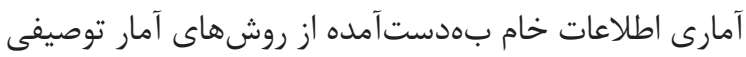
و استنباطى استفاده شد. از آمار توصيفى براى محاسبه فراوانىها، تعيين شاخصهاى مركزى و يراكندگى استفاده

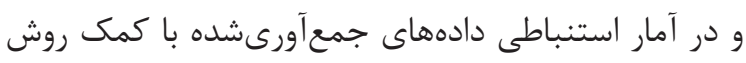
تحليل كوواريانس تكمتغيرى و با استفاده از نرمافزار نسخه r T تجز يهوتحليل شد.

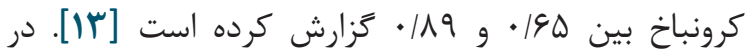

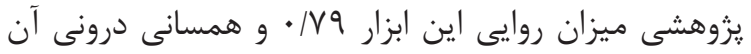

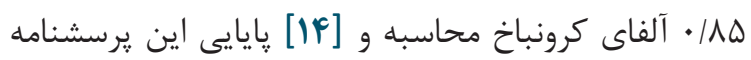

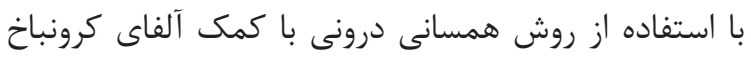

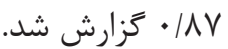

\section{ير سشنامة كيفيت زندكى (SF-36)}

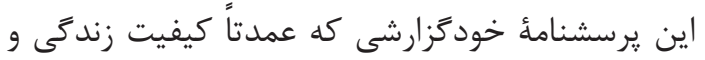
سلامت را بررسى مى كند عب عبارت دارد و 1 قلمرو عملكرد

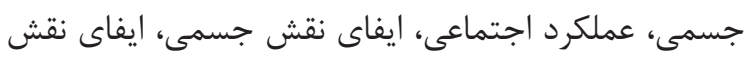

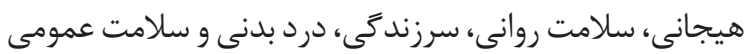

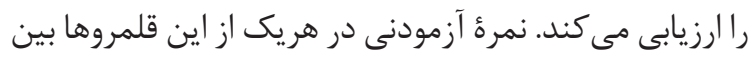

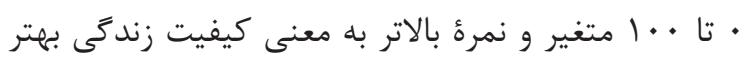

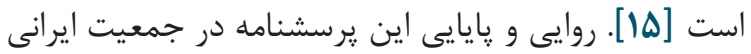

معرفى برنامه به شركت كنند زند

جلسئ اول

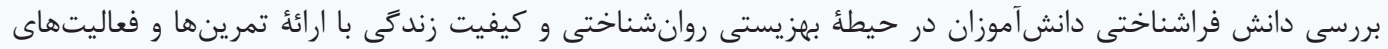

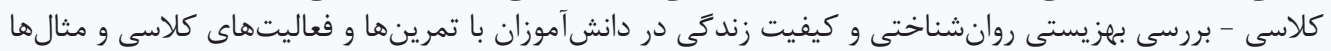

جلسؤ دوم

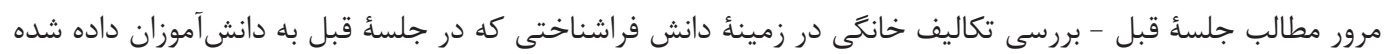

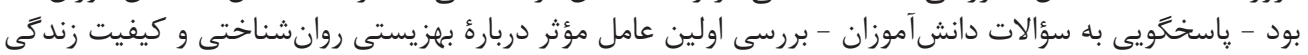
جلسأُ سوم

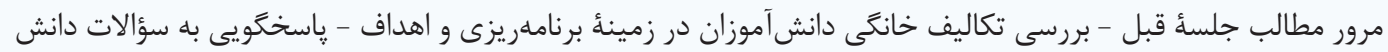

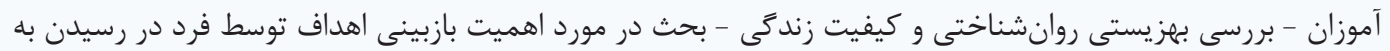
اهداف نهايى جلسؤ جهارم

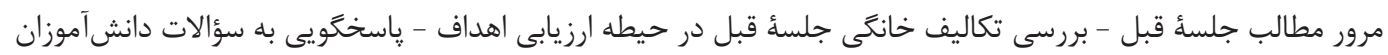

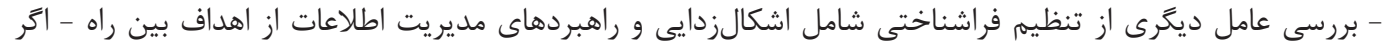

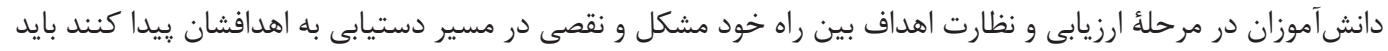

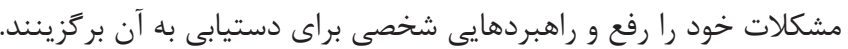

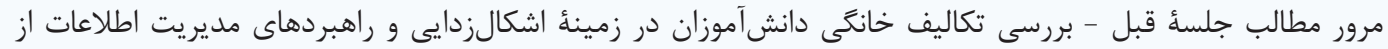

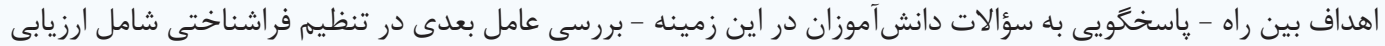

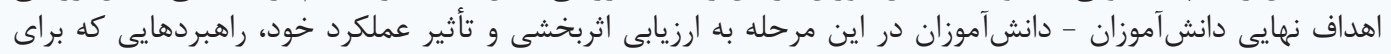

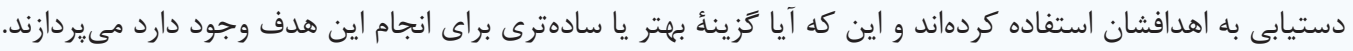

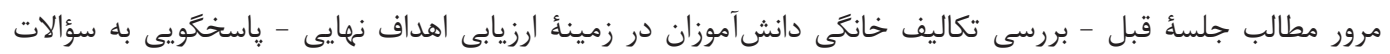

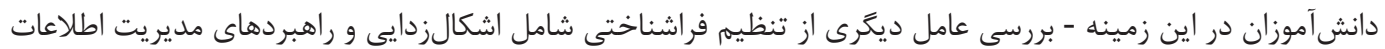

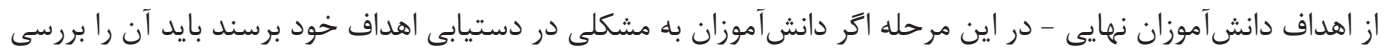

جلسئ هفتمم

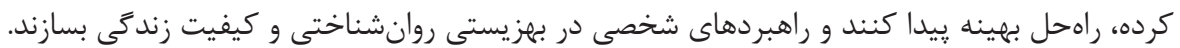

جلسئ پنجم

جلسة ششم

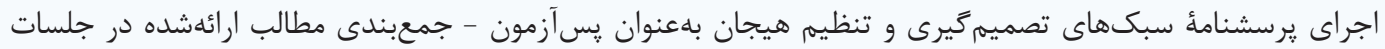

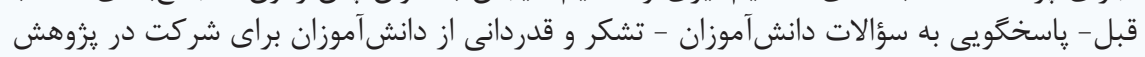

جلسؤ هشتم 


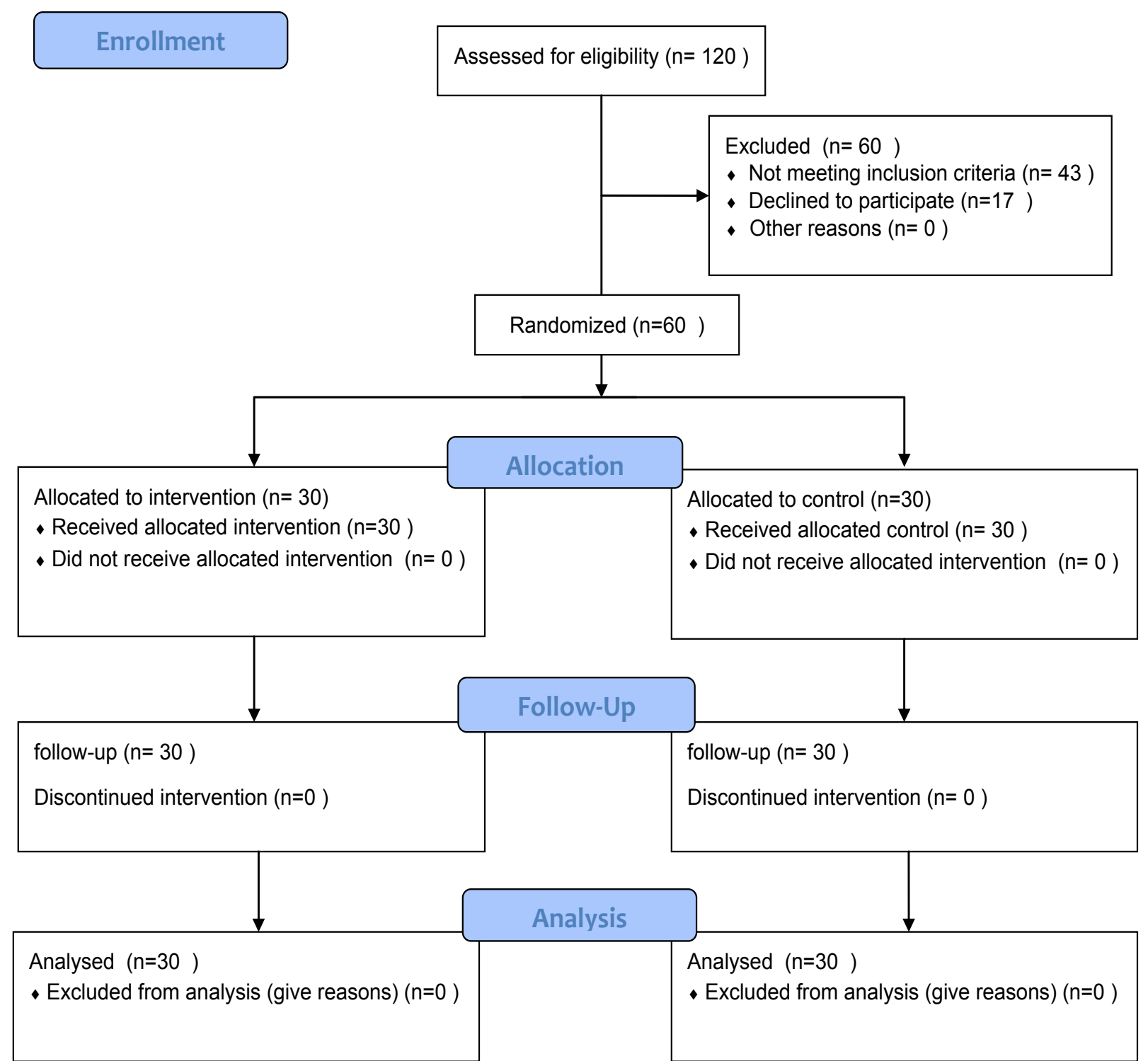

نمودار I. CONSORT تخصيص آزمودنىها

آزمايش و كنترل حداقل از لحاظ يكى از متغيرهاى وابسته

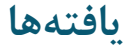

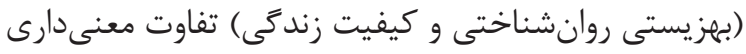

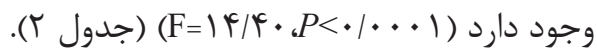

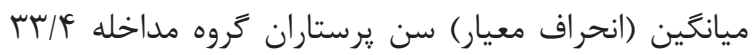

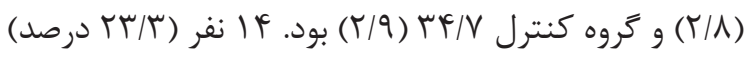

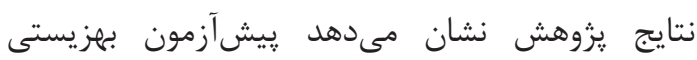

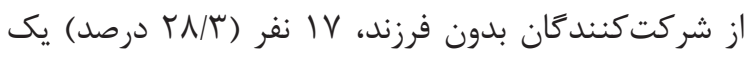

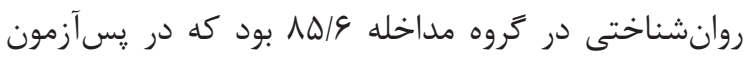

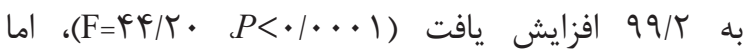

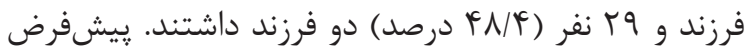

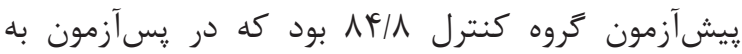

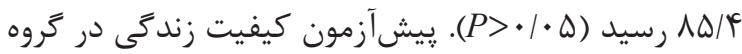
مداخله VI/ بود كه در يس آزمون به 19/V افزايش يافت

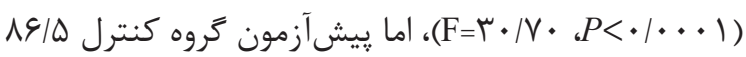

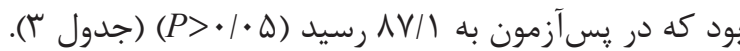
تساوى واريانسهاى نمرات در دو گروه آزمايش و كنترل

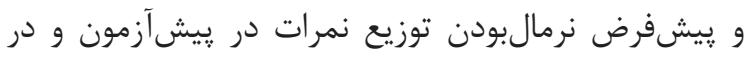

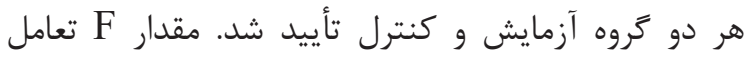
براى يكسانبودن شيب خط رَرسيون براى همأ متغيرهاى

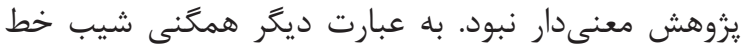

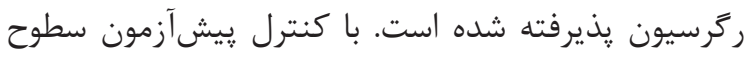

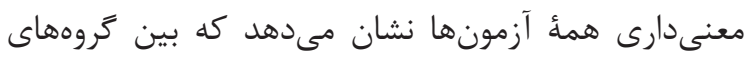


جدول r. ميانغين (انحراف معيار) نمرات متغيرهاى يثروهش در پيش آزمون و پِ آزمون

\begin{tabular}{|c|c|c|c|c|}
\hline \multirow[b]{2}{*}{$P$} & يس آزمون & بيش آزمون & & \multirow[b]{2}{*}{ متغير } \\
\hline & 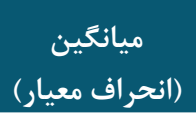 & 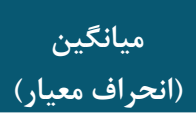 & تروه & \\
\hline$\cdot 1 \cdots \cdot 1$ & $99 / 9(1))$ & $\Lambda \bowtie / \varphi(\mid r / \Gamma)$ & مداخله & \multirow{2}{*}{ بهزيستى روانشناختى } \\
\hline$\cdot \mid \Delta \Phi$ & $\Lambda \Delta / \mathcal{F}(\mid Y / \Lambda)$ & $\Lambda F / \Lambda(\Lambda / \Lambda)$ & كنترل & \\
\hline$\cdot 1 \cdots 1$ & $\wedge ৭ / \vee(\Upsilon \cdot / \Delta)$ & $\checkmark \backslash / T(19 / V)$ & مداخله & \multirow{2}{*}{ كيفيت زندگى } \\
\hline 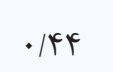 & $\wedge V / \backslash(I Y / q)$ & $\Lambda \varepsilon / \Delta(\mid \mathcal{F} / \varphi)$ & كنترل & \\
\hline
\end{tabular}

جدول r. نتايج تحليل كواريانس يكىاهه بر يس آزمون ميانكَين نمرات بهزيستى روانشناختى و كيفيت زندكى تروههاى آزمايش و كنترل با كنترل پِيش آزمون

\begin{tabular}{|c|c|c|c|c|c|c|}
\hline $\boldsymbol{P}$ & $\mathbf{F}$ & ميانكَين مجذورات & درجهُ آزادى & مجموع مجذورات & منبع تغييرات & متغير \\
\hline$\cdot 1 \cdots 1$ & ITV/VF & $\Lambda \wedge V \uparrow / \cdot 1$ & 1 & $\Lambda \Lambda V \psi / \cdot 1$ & ي پيش آزمون & \multirow{3}{*}{ بهزيستى روانشناختى } \\
\hline \multirow[t]{2}{*}{$\cdot \cdots \cdot 1$} & $F \& / T$. & $r \cdot v \cdot r q$ & 1 & $r \cdot v \cdot r q$ & كروه & \\
\hline & & $99 / 49$ & $r V$ & $r \Delta V \cdot / \Lambda \Lambda$ & خطا & \\
\hline$\cdot|\cdots|$ & $111 / 91$ & Fq./VG & 1 & $19 \cdot / V q$ & بيشآزمون & \multirow{3}{*}{ كيفيت زندگى } \\
\hline$\cdot 1 \cdots \cdot 1$ & $r \cdot / v \cdot$ & ITE/KT & 1 & ITE/TT & كروه & \\
\hline & & $F / 11$ & TV & IDT/KT & خطا & \\
\hline
\end{tabular}

احساس نشاط و سرزندگى است كه اين شاخص با احساس

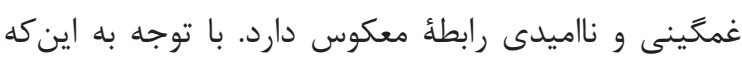

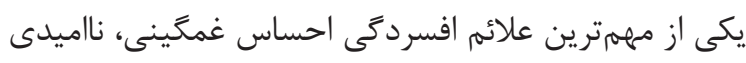

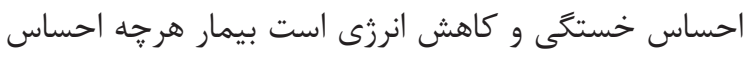

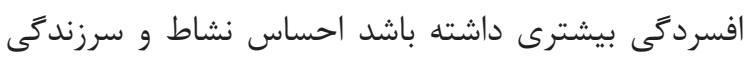

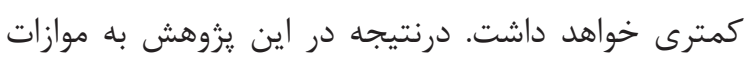

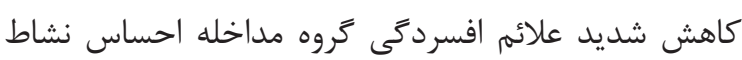

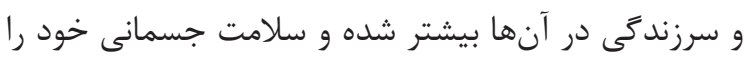

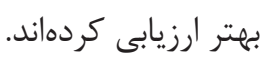
از آنجايى كه كانون اصلى درمان فراشنى فراشناختى غلبه بر نشخوارهاى ذهنى و عقايد مثبت و منفى در مورد آنسي آنهاست

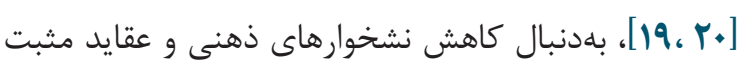

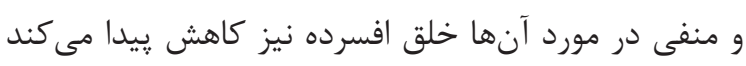

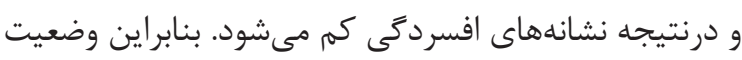

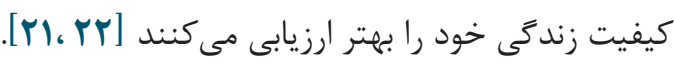
نتايج اين يزوهش با نتايج يزوهش

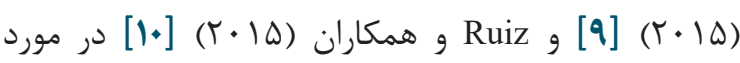

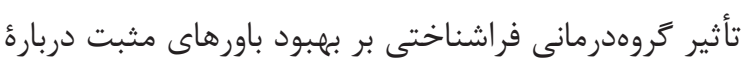

اين يزوهش نشان مىدهد آموزش فراشناخت بهزيستى

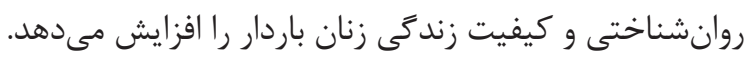

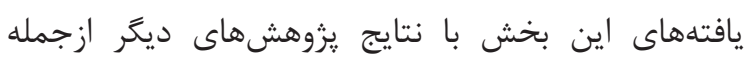
و هarhoon

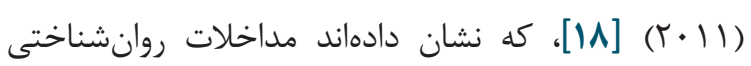

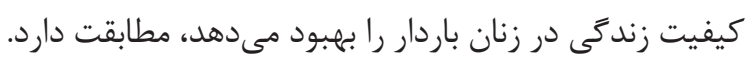

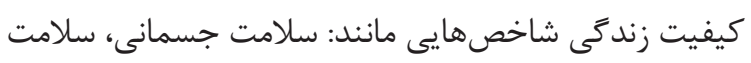

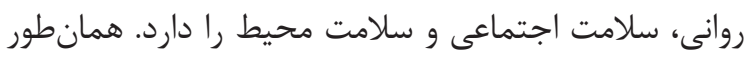

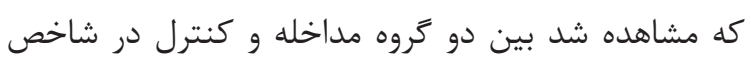
سلامت جسمانى تفاوت معنى دارى وجود دارد.

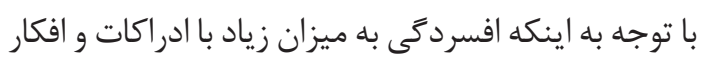

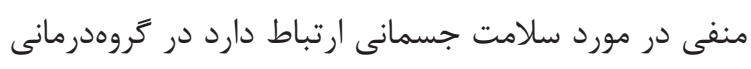

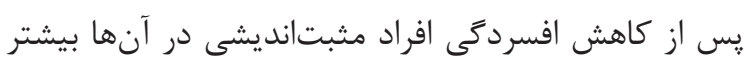

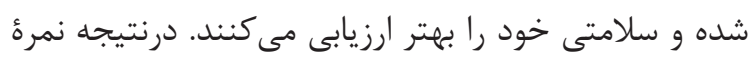

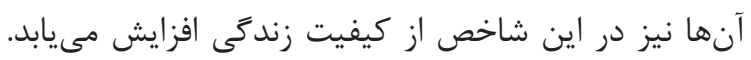

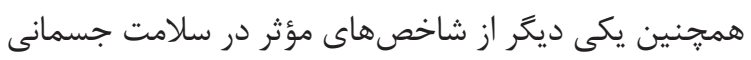


البته بعد از توضيح اين كه اطلاعات زنان باردار محرمانه خواهد

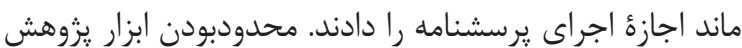
به يرسشنامه يكى ديخر از محدوديتهاى اين يزوهش است، زيرا ممكن است با صداقت پاسخ ندهند يا دقت كافى در پاسخدادن باه يرسشنامهها نداشته باشند. نتيجه تَيرى آموزش فراشناخت در بهبود بهزيستى روانشناختى و افزايش

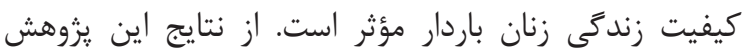
مىتوان براى بهبود بهزيستى روانشناختى و كيفيت زندگى زنان باردار استفاده كرد.

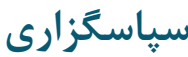

اين مقاله بركرفته از طرح يزوهشى مصوب دانشگاه پيام نور با كد كميتهُ اخلاق IR.PNU.REC 1395.79520 از كميتهٔ اخلاق

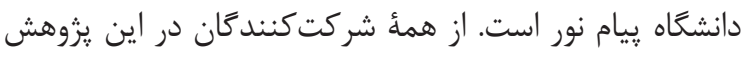
تشكر و قدردانى مى كنيم. تعارض در منافع بين نويسندَان هيجَّونه تعارضى در منافع وجود ندارد.

\section{References}

1. Kessler AM, Stein MK, Schunn CD. Cognitive demand of model tracing tutor tasks: Conceptualizing and predicting how deeply students engage. Technology, Knowledge and Learning. 2015; 20(3):317-337.

2. Abdollahi A, Hosseinian S, Asmundson GJ. Coping Styles Mediate Perfectionism Associations with Depression Among Undergraduate Students. The Journal of general psychology. 2018; 1-3.

3. Gustafsson MK, Stafne SN, Romundstad PR, Mørkved S, Salvesen KÅ, Helvik AS. The effects of an exercise programme during pregnancy on health-related quality of life in pregnant women: a Norwegian randomised controlled trial. BJOG: An International Journal of Obstetrics \& Gynaecology. 2016; 123(7):1152-1160.

4. Dunkel Schetter C. Psychological science on pregnancy: stress processes, biopsychosocial models, and emerging research issues. Annual review of psychology. 2011; 62:531-558.

5. Lyndon MP, Henning MA, Alyami H, Krishna
افسردگى، كيفيت زندگى، پاسخدهى نشخوارى، فراشناخت و اثربخشى درمان فراشناختى بر علائم افسردىى و كيفيت زندگَ بيماران افسرده اساسى همسوست. همجنين اين نتايج با يافتههاى يزوهش Hasson-Ohayon و همكاران (ها • ץ) [11] در مورد بيشبينى كيفيت اجتماعى زندگى در افراد مبتلا به به اسكيزوفرنى بر اساس ظرفيت فراشناختى همسوست.

بلهور كلى اين يافته با يزوهش Barahmand و همكاران

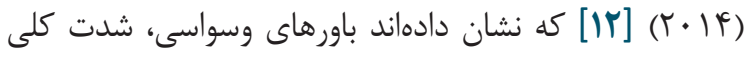
وسواس فكرى و باورهاى فراشناختى با كيفيت كلى نمرات زندكى ارتباط دارد همسو است. درنتيجه با انجام تكنيكها و

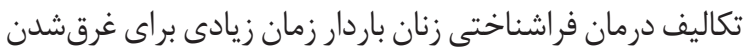
در افكار و خاطرات منفى و نشخوارهاى فكرى منفى نخواهند

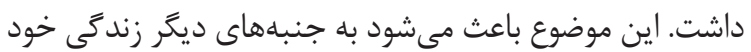
بيشتر توجه كنند و روابط اجتماعى خود را گسترش دهند. به اين ترتيب بهزيستى روانشناختى خود را افزايش دهند. اين يزوهش محدود به يرستاران شاغل به بيمارستان نمازى

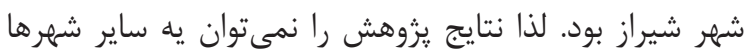
و بيمارستانها تعميم داد. دشوارى در جلب رضايت مسئولان بيمارستان نمازى شهر شيراز از ديخر محدوديتهاى يزوهش بره بود كه روند شروع كار اجرايى يرسشنامه را كمى دشوار كرد.
S, Zeng I, Yu TC, et al. Burnout, quality of life, motivation, and academic achievement among medical students: A person-oriented approach. Perspectives on medical education. 2017; 6(2):108-114.

6. Joseph RP, Royse KE, Benitez TJ, Pekmezi DW. Physical activity and quality of life among university students: exploring self-efficacy, self-esteem, and affect as potential mediators. Quality of life research. 2014; 23(2):659-667.

7. Normann N, Emmerik AA, Morina N. The efficacy of metacognitive therapy for anxiety and depression: A meta-analytic review. Depression and Anxiety. 2014; 31(5):402-411.

8. Capobianco L, Reeves D, Morrison AP, Wells A. Group Metacognitive Therapy vs. Mindfulness Meditation Therapy in a Transdiagnostic Patient Sample: A Randomised Feasibility Trial. Psychiatry research. 2018; 259:554-561.

9. Wells A, Walton D, Lovell K, Proctor D. Metacognitive therapy versus prolonged exposure in adults with chronic post-traumatic stress disorder: A parallel randomized controlled trial. Cognitive Therapy and Research. 2015; 
39(1):70-80.

10. Ruiz FJ, Odriozola-González P. Comparing cognitive, metacognitive, and acceptance and commitment therapy models of depression: A longitudinal study survey. The Spanish journal of psychology. 2015; 18.

11. Hasson-Ohayon I, Avidan-Msika M, MashiachEizenberg M, Kravetz S, Rozencwaig S, Shalev $\mathrm{H}$, Lysaker PH. Metacognitive and social cognition approaches to understanding the impact of schizophrenia on social quality of life. Schizophrenia Research. 2015; 161(2):386-391.

12. Barahmand U, Tavakolian E, Alaei S. Association of Metacognitive Beliefs, Obsessive Beliefs and Symptom Severity With Quality of Life in Obsessive-Compulsive Patients. Archives of psychiatric nursing. 2014; 28(5):345-351.

13. Ryff CD. Psychological well-being revisited: Advances in the science and practice of eudaimonia. Psychotherapy and psychosomatics. 2014; 83(1):10-28.

14. Omidi A, Fini MS, Akbari H, Akasheh G. The Effects of Mindfulness-based Stress Reduction on Emotional Regulation and Psychological Well-being of Iranian Veteran's Homemakers with Secondary Posttraumatic Stress Disorder. Archives of Trauma Research. 2017; 6(4):82.

15. Lacson E, Xu J, Lin SF, Dean SG, Lazarus JM, Hakim RM. A comparison of SF-36 and SF-12 composite scores and subsequent hospitalization and mortality risks in long-term dialysis patients. Clinical Journal of the American Society of Nephrology. 2010; 5(2):252-560.

16. Haghpanah S, Nasirabadi S, Ghaffarpasand F, Karami R, Mahmoodi M, Parand S, Karimi M. Quality of life among Iranian patients with beta-thalassemia major using the SF-36 questionnaire. Sao Paulo Medical Journal. 2013; 131(3):166-172.

17. Parhoon H, Moradi A, Hatami M, parhoon K. Comparison of the Brief Behavioral Activation Treatment and Meta-cognitive Therapy in the Reduction of the Symptoms and in the Improvement of the Quality of Life in the Major Depressed Patients, journal of research in psychological health. 2012; 6(4):36-52. [Full text in Persian].

18. Neshatdost HT, Nilfroshzadeh MA, Dehghani F, Molavi H. Effectiveness of cognitive behavior stress management therapy on patient's quality of life with alopecia in skin disease and leishmaniusis research current of Isfahan,
Journal of Arak University of medical science. 2011; 12:125-132.

19. Trauelsen AM, Gumley A, Jansen JE, Pedersen $\mathrm{MB}$, Nielsen $\mathrm{HG}$, Trier $\mathrm{CH}$, et al. Metacognition in first-episode psychosis and its association with positive and negative symptom profiles. Psychiatry research. 2016; 238:14-23.

20. Gorzelsky G, Driscoll DL, Paszek J, Jones E, Hayes C. Cultivating constructive metacognition: a new taxonomy for writing studies. Critical Transitions: Writing and the Question of Transfer. 2016; 12(4):215-228.

21. Hjemdal O, Hagen R, Solem S, Nordahl H, Kennair LE, Ryum T, Nordahl HM, Wells A. Metacognitive therapy in major depression: an open trial of comorbid cases. Cognitive and Behavioral Practice. 2017; 24(3):312-318.

22. Morrison AP, Pyle M, Chapman N, French P, Parker SK, Wells A. Metacognitive therapy in people with a schizophrenia spectrum diagnosis and medication resistant symptoms: a feasibility study. Journal of Behavior Therapy and Experimental Psychiatry. 2014; 45(2):280-284. 